\title{
Hoàn thiện cơ chế Đảng lãnh đạo, nhà nước quản lý, nhân dân làm chủ ở Việt Nam - Từ tiếp cận lý thuyết hệ thống xã hội
}

\author{
Nguyễn Đình Tấn* \\ Học viện Chính trị Quốc gia Hồ Chi Minh, 135 Nguyễn Phong Sắc, Cầu Giấy, Hà Nội, Việt Nam \\ Nhận ngày 10 tháng 8 năm 2017 \\ Chỉnh sửa ngày 25 tháng 9 năm 2017; Chấp nhận đăng ngày 10 tháng 10 năm 2017
}

\begin{abstract}
Tóm tắt: Lý thuyết hệ thống xã hội là một trong các lý thuyết quan trọng của xã hội học. Khả năng ứng dung nghiên cứu của nó là rất lớn. Thuyết hệ thống nhấn mạnh vào chức năng cân bằng, ổn định trật tự của xã hội; nó cũng đồng thời đòi hỏi mọi thành viên của xã hội phải phát huy tính chủ động của bản thân trong việc thực hiện các vai trò của mình song cũng đồng thời phải biết tuân thủ những đòi hỏi chung của cả hệ thống hệ thống. Thuyết hệ thống cũng nhấn mạnh vào việc mỗi cá nhân phải thực hiện không chỉ một vai trò mà là một tập hợp các vai trò (cả theo chiều "ngang" và cả theo chiều "dọc"). Một trong những nghiên cứu ứng dụng lý thuyết có ý nghĩa là việc vận dụng lý thuyết tiếp cận hệ thống vào việc hoàn thiện cơ chế Đảng lãnh đạo, nhà nước quản lý, nhân dân làm chủ. Đó là việc coi xã hội là một hệ thống lớn; trong đó bao gồm nhiều hệ thống con. Mỗi hệ thống con có những chức năng khác nhau song đồng thời lại có cùng một chức năng chung của hệ thống.
\end{abstract}

Tù khóa: Đảng lãnh đạo, nhà nước quản lý, nhân dân làm chủ, lý thuyết hệ thống xã hội

\section{Cơ chế Đảng lãnh đạo, nhà nước quản lý, nhân dân Làm chủ- Từ tiếp cận sơ đồ bốn chức năng "AGIL"}

Dưới giác độ của Xã hội học, cơ chế Đảng lãnh đạo, Nhà nước quản lý, nhân dân làm chủ bị quy định bởi vị trí và vai trò của nó trong hệ thống xã hội. Do vậy cần phải tìm hiểu thấu đáo vấn đề này. Theo quan điểm của Chủ nghĩa duy vật lịch sử của chủ nghĩa Mác- Lê nin, hệ thống chính trị là một bộ phận trong kiến trúc thượng tầng của xã hội. Kiến trúc thượng tầng này được hình thành trên cơ sở hạ tầng- hệ thống các quan hệ kinh tế (một tập hợp các quan hệ

\footnotetext{
* ĐT.: 84-912636069.

Email: nguyenanhtanxhh@gmail.com https://doi.org/10.25073/2588-1116/vnupam.4073
}

sản xuất) cùng với cơ cấu xã hội do phương thức xã hội đó quy định. Chủ nghĩa Mác - Lê nin chỉ ra rằng, phương thức sản xuất Tư bản chủ nghĩa là nền tảng trên đó hình thành hệ thống chính trị tư sản, nhà nước tư sản. Phương thức sản xuất xã hội chủ nghĩa là nền tảng của hệ thống chính trị xã hội chủ nghĩa, nhà nước pháp quyền xã hội chủ nghĩa.

Chính vị trí của hệ thống chính trị ở kiến trúc thượng tầng quy định vai trò của nó trong xã hội. vai trò thứ nhất của nó không phải làm thay cho những chức năng của các bộ phận trong cơ sở hạ tầng mà là tìm mọi cách để củng cố, bảo vệ kết cấu kinh tế - cơ sở hạ tầng của nó. Vai trò thứ hai là định hướng cho sự phát triển, đẩy nhanh mặt này hoặc kiềm chế mặt khác, tạo điều kiện tốt nhất cho sự phát triển. Vai trò thứ ba là duy trì và tăng cường tính mục 
đích và tính chất hoạt động của chế độ kinh tế mới. Lý thuyết hệ thống giúp ta hình dung cụ thể hơn vị trí của hệ thống xã hội. Theo thuyết hệ thống tổng quát, có thể phân biệt được bốn vấn đề chức năng chủ yếu của bốn chiều cạnh của của quá trình và cấu trúc hệ thống. Tương ứng với tọa độ "hướng ngoại-công cụ" là chức năng thích nghi: $\mathrm{A}$ (Adaptation). Tương ứng với tọa độ "hướng ngoại-mục tiêu" là chức năng đạt được mục tiêu $\mathrm{G}$ (Goal-Attainment). Tương ứng với tọa độ "hướng nội-mục đích" là chức năng liên kết I (Intergrative). Tương ứng với tọa độ "hướng nôi-công cụ" là chức năng duy trì khuôn mẫu và quản lý sự căng thẳng ký hiệu là L (Pattern Meintenance and tension Management) [1]. " "Theo hệ quy chiếu "hướng nội- hướng ngoại"; bất kỳ một hệ thống nào cũng cần phải đảm bảo cân bằng mối quan hệ bên trong-bên ngoài và đảm bảo sự ổn định bên trong cũng như thích nghi với bên ngoài” [1]. Như vậy, lý thuyết hệ thống tổng quát dưới dạng sơ đồ bốn chức năng có thể phân tích một hệ thống thuộc bất kỳ cấp độ nào thành các tiểu hệ thống từ cấp độ kỹ thuật đến cấp độ quản lý, thiết chế và tổng thể xã hội.

Theo Parsons [2], mỗi xã hội luôn là một chỉnh thể, một tổng thể bao gồm nhiều hệ thống "con"ở bên trong. Mỗi hệ thống có những vị trí và vai trò nhất định, đồng thời thực hiện những chức năng nhất định. Giữa các hệ thống con có những đường phân ranh để phân chia ranh giới giữa chúng. Nhờ đường phân ranh này mà các hệ thống con tồn tại một cách tương đối độc lập và không bị phá vỡ. Nhưng mặt khác các hệ thống con này không tồn tại một cách tách rời nhau, hoàn toàn cách biệt với nhau mà luôn có sự tác động qua lại lẫn nhau; thâm nhập vào nhau; chúng phải thích nghi với nhau Và cân bằng với nhau; cân bằng cả với bên trong và cân bằng cả với bên ngoài. Một hệ thống dù là nhỏ hay lớn thì cũng đều phải hướng tới cân bằng, ổn định, liên kết, thích nghi và tích hợp. Nếu không nó sẽ không thể tồn tại và phát triển bình thường được. Các hệ thống cũng luôn cần

\footnotetext{
${ }^{1}$ Lê Ngọc Hùng, Lý thuyết Xã hội học hiện đại, Hà Nội, 2013, tr.140-141.
}

được tổ chức, kiểm tra, nếu không nó sẽ bị hỗn loạn.Tuy nhiên cũng không nên tổ chức và kiểm tra quá ngặt nghèo, bởi như vậy nó sẽ không có môi trường thích hợp để hoạt động. Trong những trường hợp đó, chúng sẽ bị bó buộc, thiếu cơ hội và điều kiện để phát triển. Bởi vậy, chúng ta cần phải tạo ra những hành lang an toàn, rộng rãi để các thành viên, tổ chức trong hệ thống có thể vận động một cách thuận lợi dễ cơ động và sáng tạo. Một xã hội, nếu bị tổ chức một cách qúa cứng nhắc, bị "quan liêu" hóa, có quá ít những môi trường tự do để hoạt động, lúc đó sẽ dẫn đến trì trệ, xơ cứng và có nguy cơ tan vỡ. Cũng theo lý thuyết này, mỗi xã hội luôn có một số hệ thống con cơ bản và tuyệt đối cần thiết đối với sự tồn tại và phát triển của nó [3]. ${ }^{2}$ Đó là các hệ thống Kinh tế, chính trị, pháp luật, gia đình, văn hoá v.v. Trong các hệ thống con này, hệ thống chính trị là hệ thống tương đối độc lập và được coi là quan trọng nhất. Nó có vai trò đề ra những mục tiêu chung cho sự phát triển của toàn xã hội; nó tạo ra những định hướng "khung"- những điểm tựa cho những diễn đàn chung rộng lớn cho mọi thành viên của xã hội để họ được cùng nhau thảo luận, đồng thời cổ vũ, khuyến khích, thúc đẩy mọi người vươn tới những mục tiêu do hệ thống chính trị đặt ra. Sự ổn định, cân bằng hay hỗn loạn, sự năng động, phát triển bền vững hay trì trệ,... phụ thuộc rất nhiều vào những định hướng chính trị đúng đắn hay sai lệch, tiến bộ hay bảo thủ, sáng tạo, linh hoạt hay giáo điều, máy móc, của hệ thống chính trị, đặc biệt phải kể đến là hạt nhân của nó là các Đảng chính trị và nhà nước đang điều hành xã hội.

Hệ thống chính trị là một tiểu hệ thống tuyệt đối cần thiết để thực hiện các yêu cầu chức năng của cả tổng thể hệ thống xã hội. Vai trò của hệ thống chính trị là xác định mục tiêu phát triển của cả hệ thống xã hội cũng như cho từng tiểu hệ thống xã hôi cùng hướng tới sự đồng thuận với các mục tiêu chung. Đảng là một là bộ phận quan trọng nhất của hệ thống

\footnotetext{
$\sqrt{2}$ Đọc: Joachim Matthes, Một số vấn đề lý luận và phương pháp nghiên cứu con người và xã hội, Chương trình khoa học và công nghệ cấp nhà nước KX-07, H., 1994, tr.54-56.
} 
chính trị. Đảng cần đưa ra những định hướng chiến lược nhằm lãnh đạo nhà nước và toàn xã hội. Đảng phải đề ra được những đường lối và quan điểm đúng đắn cho mọi hoạt động của nhà nước và toàn xã hội. Nhà nước là người phát ngôn, là người thực thi sự lãnh đạo của Đảng. Đảng thực hiện vai trò lãnh đạo xã hội của mình thông qua nhà nước, bằng nhà nước; sức mạnh của Đảng là hiệu lực quản lý thực tế của Nhà nước. Đảng không bao biện làm thay Nhà nước mà lãnh đạo bằng đường lối, chủ trương, bằng việc giám sát, kiểm tra, kiểm soát trực tiếp, gián tiếp và thường xuyên đối với Nhà nước. Nhà nước mạnh, thì Đảng mạnh. Đảng cử những Đảng viên ưu tú của mình tham gia vào các cơ quan chức năng của nhà nước thông qua bầu cử, ứng cử dân chủ của bộ máy chính quyền nhà nước và hiệu lực lãnh đạo của Đảng chính là hiệu quả hoạt động của Nhà nước (của các cơ quan công quyền).Nhà nước là một bộ phận cơ bản của hệ thống chính trị, nó có vai trò huy động các nguồn lực và thực thi các quyền lực để thực hiện mục tiêu của cả hệ thống chính trị. Nhà nước lãnh đạo xã hội bằng các chính sách, pháp luật, các quy tắc, quy chế quy định đã được pháp luật hóa và chuẩn mực hóa. Những chính sách, pháp luật và các chuẩn mực quy tắc xã hội được thể chế hóa trên cơ sở những đương lối chiến lược, những chủ trương và những nguyên tắc lãnh đạo cơ bản của Đảng. Hệ thống chính trị có vai trò xác định mục tiêu và những định hướng chung cho cả tổng thể xã hội, cho các tiểu hệ thống khác.

\section{Thực hiện vai trò lãnh đạo nhà nước của Đảng cầm quyền}

Nhà nước ta đặt dưới sự lãnh đạo của Đảng cộng sản Việt Nam. Đối với Đảng ta, cầm quyền là một sứ mệnh lịch sử mới mẻ và khó khăn. Đảng cộng sản Việt Nam lãnh đạo nhân dân giành chính quyền (sau sự lưa chọn khách quan và nghiêm khắc của lịch sử) đã trở thành Đảng duy nhất cầm quyền. Phương thức lãnh đạo của Đảng cầm quyền đối với nhà nước được thực hiện qua các tổ chức và con đường sau đây:

\section{Qua các tổ chức của Đảng và Đảng viên:}

Đảng cộng sản Việt Nam vừa là tổ chức cao nhất ở cấp trung ương vừa bao gồm hàng vạn tổ chức cơ sở Đảng và hàng triêu cán bộ Đảng viên trong các tổ chức chính trị, kinh tế, văn hóa, xã hội. Do vậy hiệu quả lãnh đạo của Đảng còn phụ thuộc vào các tồ chức Đảng và Đảng viên ở các cương vị khác nhau mà họ đảm nhận ở các tổ chức đó. Chính hoạt động của họ sẽ góp phần quan trọng trong việc đưa đường lối, chủ trương chính sách của Đảng và Nhà nước vào cuộc sống và là lực lượng quyết định đối với việc hiện thực hóa vai trò của Đảng trong hệ thống chính trị. Là Đảng cầm quyền, mỗi cán bộ, Đảng viên của Đảng luôn thể hiện tính Đảng của mình với tư cách là một công dân, một công chức, một đại biểu dân cử. Mỗi Đảng viền, dù ở cương vị nào đều phải hoàn thành trách nhiệm Đảng viên, đề cao trách nhiệm chính trị và phải tuân thủ quy định của pháp luật. Đảng lãng đạo thông qua tổ chức Đảng và đề cao trách nhiệm Đảng viên đã trở thành yêu cầu bức thiết trong điều kiện xã hội và hệ thống chính trị đa dạng. Để bảo đảm cho các tổ chức Đảng hoạt động có hiệu quả và từng bước thể chế hóa tổ chức của Đảng, phải xây dựng cơ cấu tổ chức, chức năng, nhiệm vụ, quy chế hoạt động của các cấp ủy, sở, các cơ quan của Đảng từ trung ương đến địa phương phù hợp với chức năng ,nhiệm vụ của các tổ chức trong hệ thống chính trị. Cần đặc biệt quan tâm xây dựng đội ngũ cán bộ, Đảng viên vừa có bản lĩnh chính trị vững vàng, vừa có hiểu biết sâu sắc chuyên môn, có tư duy mới và kỹ năng về hoạt động chính trị, góp phần thành công trong công tác Đảng. Theo thuyết hệ thống, tập hợp vai chính là ở đây. Là một người vừa phải là một Đảng viên ưu tú, tuyệt đối trung thành với lý tưởng của Đảng, trung kiên với mục tiêu và các nhiệm vụ chính trị của Đảng song cũng vừa phải là một cán bộ, công chức mẫn cán, đảm nhiệm và hoàn thành xuất sắc bổn phận của một công chức; vừa phải thể hiện mình như một công dân gương mẫu, tận tụy trong việc thực hiện nghĩa vụ, bổn phận của mình. Cán bộ, Đảng viên viên chức, công chức vừa với tư cách của tổ chức Đảng, Vừa với tư cách là cơ 
quan công quyền thực hiện những vai của mình đối với nhân dân, vừa chịu sự giám sát của nhân dân, chịu sự chất vấn, phản biện của nhân dân, sự đánh giá, phê bình và phải đáp ứng những yêu cầu, đòi hỏi của nhân dân, trả lời những đòi hỏi của nhân dân trong cuộc sống dân sinh.

\section{Qua bộ máy nhà nước:}

Bộ máy nhà nước là công cụ của Đảng càm quyền ở nước ta.Đảng và Nhà nước có cùng một mục tiêu chung là xây dựng một đất nước Việt Nam "dân giàu, Nước mạnh, xã hội dân chủ, công bằng, văn minh"; đồng thời đều là "công bộc" trung thành của nhân dân; có cùng một đối tượng lãnh đạo, quản lý là nhân dânDân tộc, quốc gia.

Tất nhiên, Đảng không phải là Nhà nước. Đảng là tổ chức chính trị cao nhất của giai cấp công nhân của nhân dân lao động, tổ chức tham mưu sáng suốt, đội quân tiên phong của dân tộc, người lãnh đạo duy nhất của nhà nước, lãnh đạo trực tiếp, tuyệt đối và toàn diện Nhà nước. Nhà nước - trụ cột của hệ thống chính trị, là tổ chức công quyền mang tính cưỡng chế, là tổ chức thống nhất bao gồm cả 3 nhánh quyền lực cơ bản của nhân dân là lập pháp, tư pháp và hành pháp. Đảng cộng sản Việt Nam là Đảng cầm quyền, Đảng duy nhất, độc quyền lãnh đạo Nhà nước. Nhà nước thực hiện chức năng thể chế hóa các quan điểm, đường lối, chủ trương, của Đảng thành hiến pháp, pháp luật, chính sách, kế hoạch cụ thể để tổ chức nhân dân thực hiện. Đảng lãnh đạo Nhà nước thông qua công tác cán bộ và xây dựng đội ngũ cán bộ chủ chốt trong các cơ quan Nhà nước, đoàn thể chính trị xã hội; thực hiện đúng nguyên tắc: Đảng lãnh đạo công tác tổ chức và quản lý cán bộ.

Nhà nước thống nhất quản lý những vấn đề cơ bản của xã hội đồng thời giao quyền hạn và phân định trách nhiệm cho các ngành, các cấp của địa phương, tức là thực hiện phân cấp quản lý, giao quyền chủ động cho các cấp các ngành tổ chức thực hiện pháp luật và các văn bản pháp quy của trung ương.

Để đảm bảo sự lãnh đạo của Đảng thông qua bộ máy nhà nước một cách hiệu quả, cần tránh những xu hướng hoặc là tổ chức Đảng bao biện, làm thay, can thiệp quá sâu vào công việc thuộc chức năng, nhiệm vụ, quản lý điều hành của Nhà nước hoặc là buông lỏng sự lãnh đạo của Đảng, tách rời tổ chức cơ sở với tổ chức chính trị, kinh tế. Xây dựng Nhà nước vững mạnh thuộc về trách nhiệm của Đảng. Mọi hoạt động của Đảng Phải làm cho Nhà nước vững mạnh.

\section{Sự vận dụng tiếp cận hệ thống trong việc phát huy quyền làm chủ của nhân dân}

Lý luận phát huy quyền làm chủ của nhân dân có thể vận dụng từ lý thuyết xã hội hóa của Parsons. Theo lý thuyết hệ thống tổng quát của Parsons, câu trả lời quan trọng nhất của Xã hội học là: "Làm thế nào mà các cá nhân có năng lực thực hiện được các vai trò của họ". Theo lý thuyết hệ thống tổng quát: "Các cá nhân phát triển các năng lực thực hiện các vai trò xã hội trong quá trình xã hội hóa" $[1]^{3}$ (quá trình tương tác với người khác). Quá trình xã hội hóa chủ yếu được thực hiện qua 3 giai đoạn (qua 3 địa chỉ): Gia đình, Nhà trường, Các tổ chức xã hội.

Phát huy quyền làm chủ tập thể của nhân dân có nguồn gốc sâu sa từ một nhà nước dân chủ. Thuyết hệ thống tổng quát coi trọng sự độc lập tương đối của mỗi tiểu hệ thống, nhấn mạnh đến tính tổng thể của xã hội, đến cấu trúc xã hội, đi từ xã hội để hiểu cá nhân. Trong thuyết hệ thống không nói đến con người hành động mà coi hệ thống là một trật tự mà người ta tác động lẫn nhau, theo đòi hỏi chung của hệ thống. Parsons xuất phát từ toàn bộ trật tự , từ trình độ chung "cao" của hệ thống để đi đến con người hành động. Ở đây, hệ thống quy định con người, còn con người chỉ Là một thực thể xuất hiện như là thực hiện chức năng cuả hệ thống. Thuyết hệ thống coi con người hành động cũng là một tiểu hệ thống và bên cạnh con người cũng là một hệ thống khác. Mỗi con người lại là tổ hợp của nhiều hệ thống nhỏ hơn: văn hóa,

\footnotetext{
${ }^{3}$ Lê Ngọc Hùng, Lý thuyết Xã hội hoc hiện đại, NXB. Đại học quốc gia, H., 2013, tr.147.
} 
hành vi, đạo đức.... Mỗi xã hội là một hệ thống của hệ thống và vì vậy con người là một cái gì đó cao hơn con người. Chính vì vậy, trong thuyết hệ thống, ngoài việc tôn trọng trật tự của hệ thống, đòi hỏi phải coi trọng con người hành động, coi trong những cá nhân - mà bản thân nó cũng là một tiểu hệ thống - tổ hợp của rất nhiều hệ thống nhỏ hơn. Sự chủ động thích nghi của những con người hành động này đồng hành với việc tự nguyện tuân thủ, phục tùng những đòi hỏi chung của hệ thống là các giải pháp tất yếu cần thiết của vấn đề trật tự - một giải pháp về trât tự xã hội mà thuyết hệ thống rất nhấn mạnh. Làm chủ tập thể vì vậy là sự vận dụng sáng tạo giải pháp về trật tự của thuyết hệ thống. Con người hành động ở đây là những thực thể sáng tạo, vừa tự do, tự giác vừa ý thức đầy đủ về trách nhiệm cá nhân, tự nguyện, tự giác tuân thủ những quy tắc, chuẩn mực chung của toàn xã hội. Con người hành động ở đây không phải là những cá nhân riêng rẽ, tách bạch khỏi các cá nhân khác mà là một tập thể, một tập hợp các cá nhân đồng thời trong cùng một lúc thực hiện nhiều vai xã hội.

\section{Tài liệu tham khảo}

[1] Lê Ngọc Hùng, Lý thuyết xã hội học hiện đại, NXB. Đại học quốc gia Hà Nội, H., 2013.

[2] Talcott Parsons. The Social System. Glencoe ILLinais: The Pree.Press, 1951.

[3] Joachim Matther, Một số vấn đề lý luận và phương pháp nghiên cứu con người và xã hội, Chương trình khoa học công nghệ cấp Nhà nước KX.07, H., 1994.

\title{
Completing the Mechanism of the Party's Leadership, the State's Management and the People's Mastery in Vietnam - From the Social System Theory Approach
}

\author{
Nguyen Dinh Tan \\ Ho Chi Minh National Academy of Politics, 135 Nguyen Phong Sac, Nghia Tan, Hanoi, Vietnam
}

\begin{abstract}
Social system theory is one of the important theories of sociology. Its applicability is huge. System theory emphasizes the balancing and stabilizing function of the social order; It also requires all members of society to promote their autonomy in carrying out their roles as well as to comply with the common requirements of the whole system. The system also emphasizes that each person must perform not only one role but rather a set of roles (both "horizontally" and "vertically"). One of the major theoretical application studies is the application of system theory approach to the completion of the mechanism of the party's leadership, the state's management and the people's mastery. That is to regard the society as a large system, including many subsystems. Each subsystem has different functions, but at the same time, has the same general function of the system.
\end{abstract}

Keywords: Party's Leadership, State's Management, People's Mastery, social system theory 